\title{
STUDY ON SOIL SPECIAL VARIABILITY AND CROPS OPTIMAL LAYOUT BASED ON GIS IN THE WEST-NORTHERN PLATEAU OF HEBEI PROVINCE
}

\author{
Taking Desheng Basin in Zhangbei County as An Example
}

Lixiao Feng ${ }^{1,2,3}$, Xiong Du ${ }^{1,2,3}$, Jizong Zhang ${ }^{1,2}$, Cundong $\mathrm{Li}^{1,3}$, Lifeng Zhang $1,2,3$

${ }^{1}$ College of Agronomy, Agricultural University of Hebei, Baoding 071001, Hebei Province, P. R. China 430023

${ }^{2}$ Zhangbei Agricultural Resource and Ecological Environment Key Field Research Station, Ministry of Agriculture, Zhangjiakou 076450, Hebei Province, P. R. China 430023

${ }^{3}$ Hebei Key Laboratory of Crop Growth Regulation, Agricultural University of Hebei, Baoding, 071001, Hebei Province, P. R. China 430023

* Corresponding author, Address: College of Agronomy, Agricultural University of Hebei, Baoding 071001, Hebei Province, P. R. China, Tel: Fax: +86-312-7528113, E-mail: zlf@hebau.edu.cn

Abstract: A geo-statistics method combined with GIS was applied to study the soil special variation characteristics of a typical basin on the Northwestern Plateau of Hebei Province. It indicates that the rational crop layout is determined by the soil texture. And the crop layout optimization schemes were put forward for different production objectives based on the GIS platform with the soilcrops special co-adaptation. The results showed that basin altitude was the primary cause for the special variation of soil texture and nutrient content. The crop layout optimization schemes showed that the economic efficiency was increased by $26.9 \% \sim 48.5 \%$ in large-scale of crop production, while the economic efficiency was increased by only $8.0 \% \sim 8.5 \%$ with ecological construction of de-farming. It was concluded that the agricultural production progress should mostly rely on the renovation of farming organization system and the scale of economy should be the primary impetus for agricultural development in the Northwestern Plateau of Hebei Province.

Key words: spatial variation of soil, crop layout, soil texture, the Northwestern Plateau of Hebei Province

Please use the following format when citing this chapter:

Feng, L., Du, X., Zhang, J., Li, C. and Zhang, L., 2009, in IFIP International Federation for Information Processing, Volume 293, Computer and Computing Technologies in Agriculture II, Volume 1, eds. D. Li, Z. Chunjiang, (Boston: Springer), pp. 465-476. 


\section{INTRODUCTION}

Soil is a continuous spatial-temporal heterogeneity. The study and application of soil spatial variation regulation is the basic gist for rational land resource utilization and crop layout. The GIS technique is an effective way to allocate crops with local conditions because of its storage and analysis ability of the massive natural resource spatial data. And GIS has been widely applied from spatial distribution and variability characteristic of soils in small scale to suitable climatic regionalization of vegetations in large scale. Precise spatial data provide the basis for soil classification and management (Cambardella, 1994; Jose, 2000; Huang, 2003; Yuan, 2008). At the same time crop adaptability database based on GIS provides quick response technology to production structure adjustment and hazard prediction (Pan, 2000; Yao, 2004; Ji, 2007; Yao, 2008). Crop layout optimization based on soil spatial variation combined with crop adaptability has been a problem to be solved by agronomist and farming manager (Wang, 2007). The development of GIS and related cumputer technology showed a new thought for the question. This paper analyzes the soil spatial variation and its influence on crop layout of a typical geomorphic unit in northwestern plateau of Hebei Province and discusses the coupling relationship between soil and crop. And the crop layout optimization schemes for different targets were put forward to further provide the technological basis for structure and function improvement of crop production system in the northwestern plateau of Hebei Province.

\section{STUDY ZONE DESCRIPTION AND METHODS}

The northwestern plateau of Hebei Province lies at the southeast edge of Inner Mongolia plateau. The altitude ranges from $1300 \mathrm{~m}$ to $1600 \mathrm{~m}$. And the area is characterized as slope land and shoaly land with staggered distribution. The wavy terrain results in remarkably special differentiation of the secondary resource with the characteristic of soil special differentiation. Because of the long-time unscientific and predatory agricultural production it caused severe soil erosion and desertification. It is one of the nearest resources for sand-dust to Beijing. So crop spatial layout optimization aimed to economic development and ecological restoration has become one of the most important active demands for regional society development.

The study zone lies on the eastern slope of Desheng Village, Zhangbei County, Hebei province, China and its terrain is relatively independent $\left(41.19^{\circ} \mathrm{N}, 14.84^{\circ} \mathrm{E}\right.$ and $1405.2 \sim 1416.2 \mathrm{~m}$ above the sea level). The total area of the zone is $242762.8 \mathrm{~m}^{2}$. It includes $219900 \mathrm{~m}^{2}$ of farmland, $12536.9 \mathrm{~m}^{2}$ of low grassland, $6256.3 \mathrm{~m}^{2}$ of forestland, and $4069.6 \mathrm{~m}^{2}$ other-use lands. Crops 
are mainly oat, sugar beet, potato, kidney bean and forage maize. The natural conditions in Desheng Basin represent the northwestern plateau of Hebei Province.

\section{STUDY METHODS}

Using the Ag GPS-132 differential receiver made by Trimble Corporation, the Desheng Basin was divided into seventy-eight nodes with one node of $50 \mathrm{~m} \times 50 \mathrm{~m}$ and measured with located position (Fig.1). Each node measured the total nitrogen content, available phosphorus, available potassium and organic matter contents and soil mechanical composition in the upper $20 \mathrm{~cm}$ soil layer. Using the software of SUPERMAP with the input value of the basin altitude, soil nutrient and its mechanical composition was quantified and interpolated. Then the map of variation in the soil was drawn.

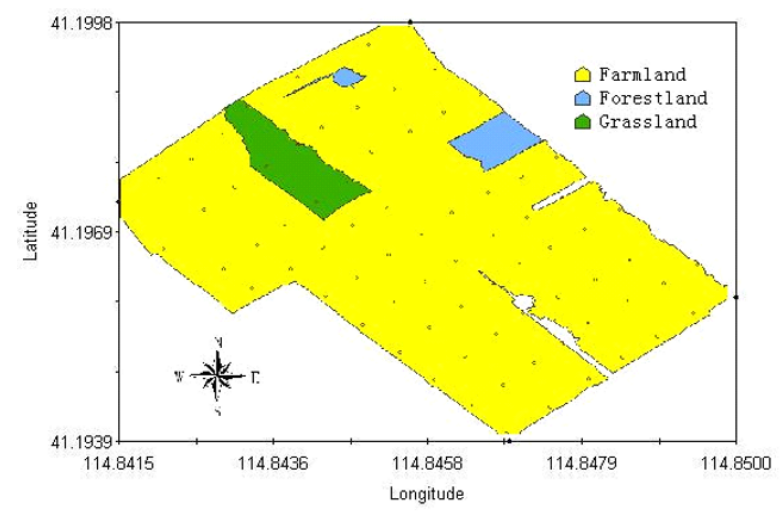

Fig. 1 The map of node distribution

The soil organic matter content, total nitrogen content, available phosphorus content and available potassium content were determined by Potassium Dichromate Titrimetric Method, Semi-Micro Kjeldahl Method, $\mathrm{NaHCO}_{3}$ extraction-ammonium molybdate-tartaric emetic-ascorbic acid colorimetry, and ammonium acetate extracting-flame spectrophotometry method, respectively. Soil mechanical composition was determined by hydrometer method.

The yield of different crops was actually measured through three sample areas of $1 \mathrm{~m}^{2}$ in each node. The cost and price of crop product were obtained through household investigation. Crop layout was designed with linear optimization. 


\section{RESULTS AND ANALYSES}

\subsection{The spatial variation of soil characteristics}

Fig.2 showed that the altitude of Desheng basin fluctuated from $1405.2 \mathrm{~m}$ to $1416.2 \mathrm{~m}$ with a low height difference and gentle incline from $0^{\circ}$ to $5^{\circ}$. The mid and northwest part of the basin was lower, and the other part was higher, so the terrain of the basin formed a dust-pan shape. In small scale, the soil formation process and mechanism was similar, but due to terrain difference, substance and energy were redistributed in different nodes, and resulted in the variance of soil texture and nutrient in the basin. The soil organic matter, total nitrogen, and available potassium contents in the low mid and northwest parts of the basin were higher than those in the other parts, and with increase of altitude along the slope the soil nutrient content decreased (Fig.3, Fig.4, and Fig.5). Soil clay content in the lower mid part was also higher than the other parts of the basin except the mid part, in which the soil clay content decreased due to higher altitude (Fig.7). There was no rule for the change of available phosphorus content because of the poor movement of phosphorus and different fertilizer application in different nodes (Fig.6).

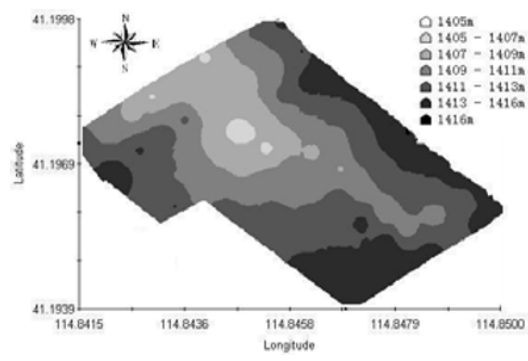

Fig.2 The contour map of Desheng Basin altitude

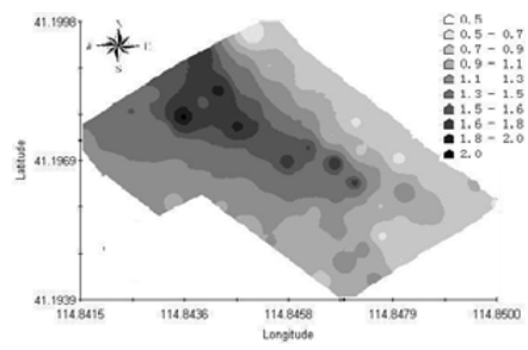

Fig.4 The contour map of the total nitrogen content in Desheng Basin

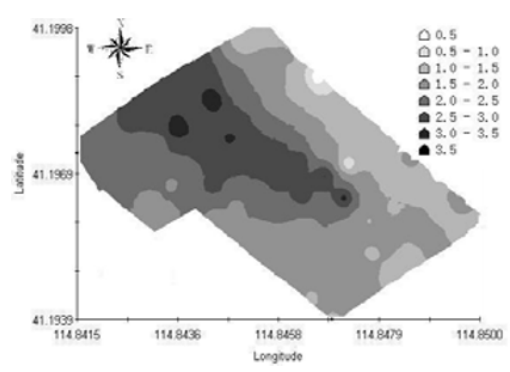

Fig.3 The contour map of the soil organic matter in Desheng Basin

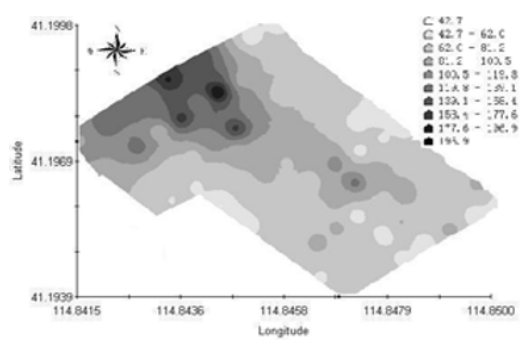

Fig. 5 The contour map of the available potassium content in Desheng Basin 


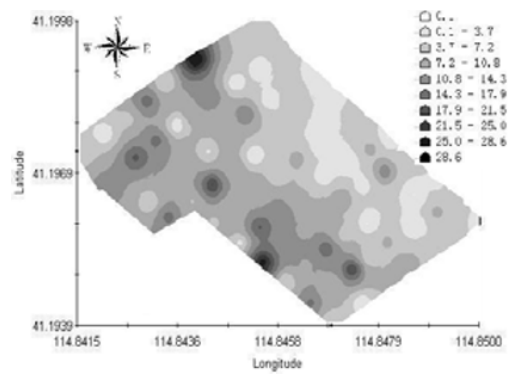

Fig.6 The contour map of available phosphorus in Deshng Basin

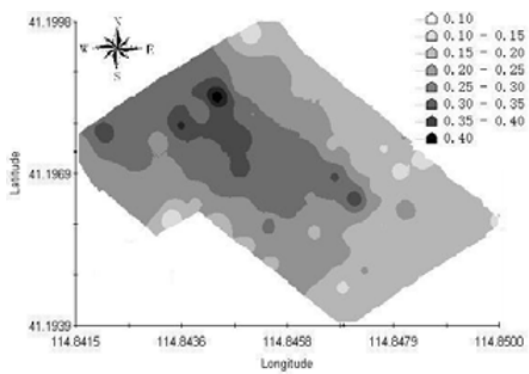

Fig7 The contour map of soil clay in Deshng Basin

Since the soil formation process was continuous in time domain, the soil texture change was continuous in space domain. The Semivariance analysis of soil characteristic data showed that soil nutrients and texture were significantly correlated with the altitude of the basin, and available phosphorus content in the soil was moderately correlated with the altitude. In small scale in the soil formation factors, the climate and soil parent material were consistent, so the difference between different nodes attributed to the difference of the terrain and altitude of the basin (Table 1).

Table1. Semivariogram models of soil nutrients and corresponding parameters

\begin{tabular}{lccccccc}
\hline \multicolumn{1}{c}{ Item } & Theory model & Nugget & Still & Nugget/Still (\%) & $\mathrm{R}^{2}$ & RSS & Range $(\mathrm{m})$ \\
\hline $\begin{array}{c}\text { Organic matter } \\
(\mathrm{g} / \mathrm{kg})\end{array}$ & Exponential & 0.1030 & 1.3050 & 13.01 & 0.96 & 0.0372 & 57 \\
$\begin{array}{c}\text { Total nitrogen } \\
(\mathrm{g} / \mathrm{kg})\end{array}$ & Exponential & 0.1570 & 1.8030 & 8.71 & 0.94 & 0.0813 & 114 \\
$\begin{array}{c}\text { Available phosphorus } \\
(\mathrm{mg} / \mathrm{kg})\end{array}$ & Exponential & 0.7260 & 1.4530 & 49.97 & 0.80 & 0.0414 & 180 \\
$\begin{array}{c}\text { Available potassium } \\
(\mathrm{mg} / \mathrm{kg})\end{array}$ & Spherical & 0.2730 & 2.3860 & 11.44 & 0.92 & 0.173 & 125 \\
$\begin{array}{l}\text { Soil clay } \\
(\%)\end{array}$ & Exponential & 0.255 & 1.407 & 18.12 & 0.921 & 0.0638 & 75 \\
\hline
\end{tabular}

The correlation analysis of soil characteristic data in each node showed that soil total nitrogen content, available potassium content, organic matter content, soil texture and altitude were significantly inter-correlated, but intercorrelation between available phosphorus and other soil characteristic was not remarkable (Table2). Soil formation was a complicated and long process, the soil texture, especially the composition proportion of physical clay, directly affects formation of soil aggregated structure, nutrients mineralization and fertilizer-water preserving capability of soil. Under the condition of little human activity, the soil texture affected and determined its nutrients content. For the farmland with extensive management in the basin, the soil texture was the effective classification standard. 
Table 2 The correlation analysis of the soil characteristic data

\begin{tabular}{|c|c|c|c|c|c|c|}
\hline Item & $\begin{array}{l}\text { Organic matter } \\
(\mathrm{g} / \mathrm{kg})\end{array}$ & $\begin{array}{l}\text { Total nitrogen } \\
(\mathrm{g} / \mathrm{kg})\end{array}$ & $\begin{array}{c}\text { Available } \\
\text { phosphorus } \\
(\mathrm{g} / \mathrm{kg})\end{array}$ & $\begin{array}{c}\text { Available } \\
\text { potassium } \\
(\mathrm{g} / \mathrm{kg})\end{array}$ & $\begin{array}{c}\text { Soil clay } \\
(\%)\end{array}$ & $\begin{array}{l}\text { Altitude } \\
\text { (m) }\end{array}$ \\
\hline Organic matter (g/kg) & 1 & & & & & \\
\hline Total nitrogen $(\mathrm{g} / \mathrm{kg})$ & $0.94 * *$ & 1 & & & & \\
\hline Available phosphorus (g/kg) & $0.26^{*}$ & $0.26 *$ & 1 & & & \\
\hline Available potassium $(\mathrm{g} / \mathrm{kg})$ & $0.75 * *$ & $0.77 * *$ & 0.18 & 1 & & \\
\hline Soil clay (\%) & $0.84 * *$ & $0.86^{* *}$ & 0.18 & $0.77 * *$ & 1 & \\
\hline Altitude (m) & $-0.78 * *$ & $-0.73^{* *}$ & -0.13 & $-0.65^{* *}$ & $-0.69 * *$ & 1 \\
\hline
\end{tabular}

\subsection{The crop production effect in different soil types}

The soil in the basin was generally classified into two types: sand chestnut soil and meadow chestnut soil (Shi, 1995). The classification standard was too simple and rough to reflect the continuous variation of the soil texture. For example, the $<0.01 \mathrm{~mm}$ physical clay content was measured with a range between $10.7 \%$ and $43.1 \%$, while according to the soil classification system of Кацинский, the soil should be sandy loam to medium loam. According to the integration of the two classification systems, the farmland in the basin should be classified into four grades (Table 3 ).

Table3. The farmland classification and its area

\begin{tabular}{lcccc}
\hline \multicolumn{1}{c}{ Item } & Grade one & Grade tow & Grade three & Grade four \\
\hline Content of physical clay $(\%)$ & $43.1 \sim 30$ & $30 \sim 25$ & $25 \sim 20$ & $20 \sim 10.7$ \\
Soil texture & medium loam & light loam & Light-sandy loam & sandy loam \\
Area $\left(\mathrm{m}^{2}\right)$ & 7301 & 58035 & 70710 & 83853 \\
\hline
\end{tabular}

The area and distribution of each grade was shown in Fig.8. In Desheng Basin, the area of NO.4 grade of farmland was the largest in the four grades, while that of NO.1 grade was the smallest. Marsh was located in the mid of the basin and it was not suitable for farming.

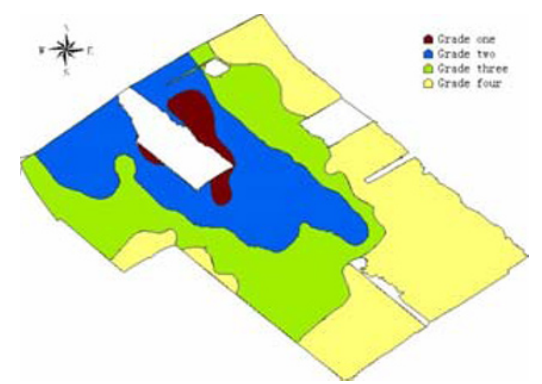

Fig. 8 The map for the farmland classification in Desheng Basin 
The terrain characterized as soil texture change affected crop yields by water and soil resource redistribution. Table 4 showed that the yields of sugar beet, oat and forage maize in different grade of farmland decreased as the soil texture became inferior. The yields of potato and kidney bean in the farmland of NO.2 grade were highest among all the grades of farmland. So these two crops were adaptive to sandy soil. There was significant difference among the yields of crops in different soil texture types of farmland. Under the condition of current extensive management, the difference of crop yields reflected the soil texture change. According to the production effect of crops in the different grade of farmland, crop re-layout should gain a better production effect than cultivation technology renovation.

Table 4. The production effect of the crops in different grades of farmland

\begin{tabular}{|c|c|c|c|c|c|c|}
\hline Farmland grade & Items & Sugar beet & Oat & Potato & Forage maize & Kidney bean \\
\hline \multirow{2}{*}{ Grade one } & Yield $\left(\mathrm{kg} / \mathrm{m}^{2}\right)$ & $3.825 \mathrm{a}$ & $0.177 \mathrm{a}$ & $1.633 \mathrm{a}$ & $4.078 \mathrm{a}$ & $0.152 b$ \\
\hline & Output value( $¥$ yuan/m²) & 0.629 & 0.155 & 0.39 & 0.393 & 0.106 \\
\hline \multirow{2}{*}{ Grade two } & Yield $\left(\mathrm{kg} / \mathrm{m}^{2}\right)$ & $3.219 b$ & $0.157 b$ & $1.665 \mathrm{a}$ & $3.489 \mathrm{~b}$ & $0.176 \mathrm{a}$ \\
\hline & Output value ( $¥$ yuan $/ \mathrm{m}^{2}$ ) & 0.435 & 0.095 & 0.412 & 0.299 & 0.166 \\
\hline \multirow[b]{2}{*}{ Grade three } & Yield $\left(\mathrm{kg} / \mathrm{m}^{2}\right)$ & $2.363 \mathrm{c}$ & $0.143 \mathrm{c}$ & $1.328 \mathrm{~b}$ & $2.531 \mathrm{c}$ & $0.122 \mathrm{c}$ \\
\hline & $\begin{array}{l}\text { Output value } \\
\text { ( } \text { yuan } / \mathrm{m}^{2} \text { ) }\end{array}$ & 0.161 & 0.053 & 0.183 & 0.146 & 0.031 \\
\hline \multirow[b]{2}{*}{ Grade four } & Yield $\left(\mathrm{kg} / \mathrm{m}^{2}\right)$ & $1.931 \mathrm{~d}$ & $0.137 \mathrm{~d}$ & $1.1 \mathrm{c}$ & $1.721 \mathrm{~d}$ & $0.103 \mathrm{~d}$ \\
\hline & $\begin{array}{l}\text { Output value } \\
\text { ( } ¥ \text { yuan } / \mathrm{m}^{2} \text { ) }\end{array}$ & 0.023 & 0.034 & 0.028 & 0.016 & -0.017 \\
\hline
\end{tabular}

\subsection{Optimization strategy for crop layout}

Table 5 and Fig.9 12 showed the results of crop layout optimization with the linear programming method according to the soil texture. Under the precondition that the total yield of the crops would not decrease and the cultivated area of all grades of the farmland would be decreased with equal ratio. The Optimization Scheme I could decrease cultivated farmland area (L) by $6.8 \%$ and the economic efficiency (B) was increased by $8.0 \%$.

It indicated that the project of returning cultivated land to forest and grass without subsidy from government could be carried out with technical approach. The land equivalent ratio $\left(\mathrm{L}^{\prime}\right)$ after crop layout optimization was only 1.073 indicating that the current crop layout was basically reasonable and the farmland was basically reasonably utilized. The straight strip planting along slope was the primary cause for restricting yield. The traditional farming mode has made the farmland basically play its productive potential.

Under the precondition that the total yield of the crops would not decrease and the farmland was cultivated with the minimum area, with the 
Optimization Scheme II crops should be first planted in the farmland of grade one to three and part of the NO.4 grade farmland was left for defarming with $17513 \mathrm{~m}^{2}$, i.e., by the crop layout optimization the de-farming area occupied $7.9 \%$ of the total farmland. At the same time, the economic efficiency was increased by $2612 ¥$ with an increase ratio of $8.5 \%$. So it was concluded that carrying out de-farming with technical approach could make economic efficiency increased by only $8.0 \% \sim 8.5 \%$ and in closed ecosystem of returning farmland to grass and/or forest was short of impetus for economic profit.

Table5. Optimization scheme for crop layout

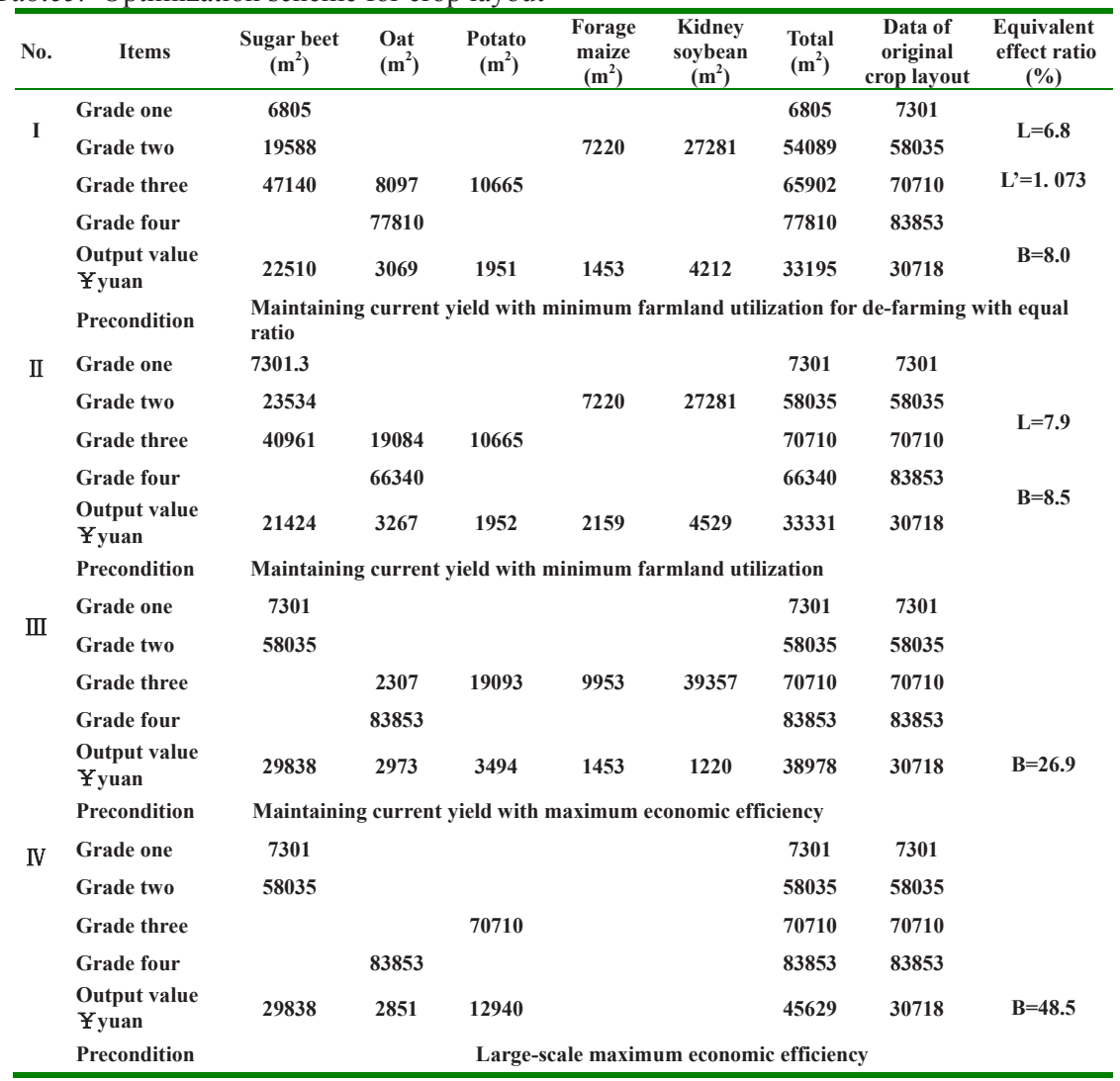

Under the precondition of maintaining current yield of crops to pursue maximum economic profit, the Optimization Scheme III could increase the economic efficiency by $26.9 \%$. The kind of crop layout need to break down the current crop planting pattern with straight strip planting along slope and farmland use pattern to realize scale profits by renovating farmland distribution modes. According to the standard that pursuing maximum 
economic profit was the unique objective without affecting the original crop layout and productive effect, the Optimization Scheme IV could increase the economic efficiency by $48.5 \%$ compared with the original crop layout, but the new crop layout need crop production to realize complete marketization, large-scale and independent management.

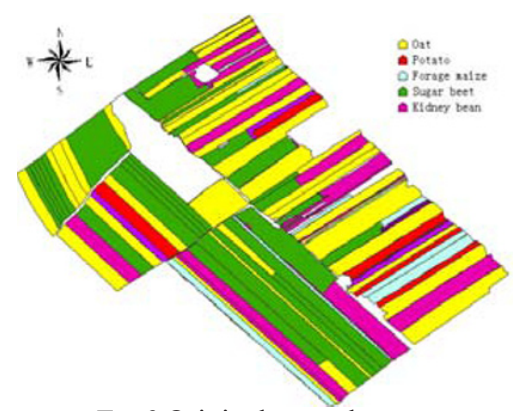

Fig.9 Original crops layout

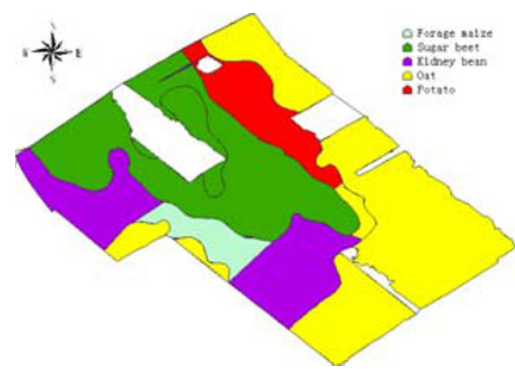

Fig11 Optimization Scheme II

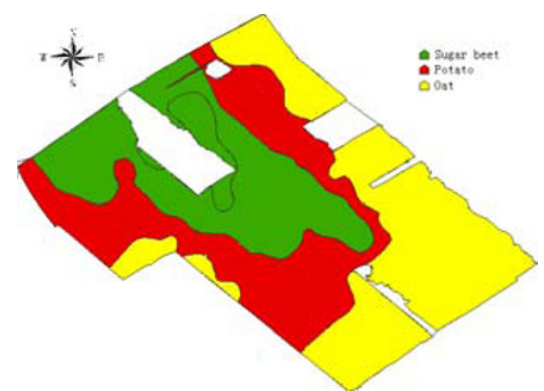

Fig.10 Optimization Scheme I

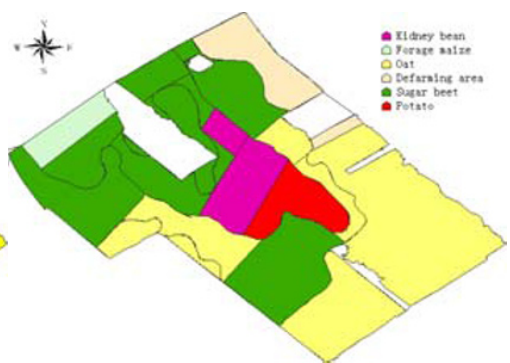

Fig. 12 Optimization Scheme III

\section{CONCLUSIONS}

In the typical basin of the northwest Plateau of Hebei Province the soil texture was significantly correlated with the terrain and altitude of the basin. Furthermore, the soil nutrient contents were significantly correlated with the soil texture. The soil clay content was the most stable factor of soil texture, and it should be regarded as the basic criteria for distinguishing soil types.

There were significant differences among the yields of crops in different soil texture types of farmland. The difference reflected the soil texture change. In the current closed ecosystem, the economic efficiency could be increased by $26.9 \%$ by renovating the farming technologies, but by building open agro-system, especially by rationally regional crop layout in large-scale would increase the economic efficiency by $48.5 \%$. Implementing de-farming with the production technology renovation could increase the economic 
efficiency by only $8.0 \% \sim 8.5 \%$, so returning farmland to grass and/or forest has to rely on subsidy from government. So in the Northwestern Plateau of Hebei Province the agricultural development should rely on organization system renovation of agricultural production to a greater extent. Large-scale economy would become a new economic growth point for agricultural development.

\section{DISCUSSION}

The geo-statistics method based on spatial correlation theories effectively illuminated the special relation and difference between different soil samples, and could reflect the special characteristics and variation rules between crops and soils more precisely than traditional statistical method (Cambell,1978; Webster, 2000; Jiang,2001). It was the basis for developing precise agriculture. The study established a platform of special coupling between soils and crops based on special variation of soil nutrients, and found the crop layout optimization schemes for different production objectives with the linear programming method. The united application of geo-statistics and GIS technology and linear programming method realized the crop optimization layout accurately. The study should be regarded as a significant attempt to change "black-box operation" into "white-box control" in precise agriculture application for crop production.

Soil texture is an important environment factor for crop growth. In large scale, soil texture is the primary gist for soil classification and rational crop layout. But in small scale, with the enhancement in cultivation factors including water-fertilizer application and cultivating-planting practices, the soil texture effect on crop layout was easily neglected. In the northwestern plateau of Hebei Province, soil formation was affected by the terrain and wind-water erosion. There was significant difference between different soil nodes. At the same time, because of extensive agricultural production, soil texture became a relative stable factor for evaluating soil fertility level. The recent studies showed that even if on the farmland with intensive management, soil texture also significantly affected water-fertilizer use efficiency so as to be regarded as a primarily important factor for crop layout (Jiang, 2006; Li, 2007; Cui, 2007). Hence, the soil regionalization based on soil special variation possessed a significant actual-guiding role for precise agriculture development.

The analysis for crop layout optimization showed that in current closed farming system the existing crop layout basically made the farmland realize its maximum function. By the renovation of crop production technologies, the potential to further increase farming productivity was limited. The agricultural productivity could be emancipated to a great extent by breaking 
down the current crop planting pattern and realizing a large-scale crop production. However, the productivity enhancement would further rely on the organization system renovation of agricultural production. This required a perfect market mechanism and effective production-market cooperation between different regions (Zhang, 2008). In China, the traditional crop layout and regionalization regarded "the principle of adjusting measures to local conditions" as guiding ideology it neglected the function of market and organization mechanism to effectively dispose agricultural resource. Thus, the guiding function of market and organization turned weaker and weaker. Some agricultural scientists from FAO point out that most of farmland exploitation projects in some developing countries did not achieve expected effect or even failed because the projects neglected the economic and social attributes of farmland (Yu, 1994). Under the background of open agriculture, the regional agricultural predominance must be made clear, and then correct agricultural production decisions can be made. Information theory and technology provided an effective approach or thinking frame for making scientific agricultural policy.

\section{REFERENCES}

Cambardella C A, Moorman T B, Novak J M, et al. Field-scale variability of soil properties in central lowa soils. Soil Science Society of American Journal, 1994,58:1501 1511.

Cambell J.B, Spatial variation of sand content and within a single contiguous delineation of two soil mapping units. Soil Science Society of America Journal, 1978, 42: 460-464

Cui Huanhu,Wang Juanling, Ma Buzhou, et al. Affect of soil texture and rotation on wheat yield and water use efficiency on non-irrigated Farmland in South of Shanxi. Journal of Soil and Water Conservation, 2007, 21 (6): 155 158 (in Chinese)

Huang Shaowen, Jin Jiyun, Yang Liping, et al. spatial variability and regionalized managent of soil nutriemts in the grain crop region in Yutian County. Acta pedologica sinica, 2003, 40(1): 79 88 (in Chinese)

Ji Rong, Li Dianmo, Xie Baoyu, et al. Research on soil spatial heterogeneity based on Locusta migratoria manilensis egg pods spatial pattern in coastal locust areas. Acta Ecologica Sinica, 2007, 27 (3): 1019 1025. (In Chinese with English abstract)

Jiang Cheng, Yang Liping, Jin Jiyun, et al. Soil nutrients variability and rational sampling quantity. Plant Nutrition and Fertilizer Science, 2001,7(3): 262 270

Jiang Peifu,Lei Tingwu, Vincent F Bralts, et al. Effects of soil textures and emitter material on the soil water movement and efficiency of negatively pressurized irrigation system]. Transactions of the CSAE, 2006, 22(4): 19 22 (in Chinese)

Jose A Amador, Yong Wang, Mary C Sarim, et al. Fine-scale spatial variability of physical and biological soil properties in Kingston, Rhode Island. Geoderma, 2000, 98: 83 94

Li Chaohai, Wang Qun, Mei Peipei, et al. Characteristics of nutrient absorption and distribution of maize under different soil textures. Plant Nutrition and Fertilizer Science, 2007, 13(4): 561 568 (in Chinese) 
Pan Xuebiao, Li Kerang.Analysis on the temporal and spatial change of cotton production development in Xinjiang based on GIS. Arid land geography, 2000, 23(3):199 206

Shi Shulun, Wang Dianwu, Wen Hongda. Study on farmland type and its productivity in the plateau in the northwest of Hebei Province. In: Liu Shuqing, Zhang Lifeng. Research on Dryland Farming. Beijing: Chain Science and Technology Press, 1995: 38 43 (in Chinese)

Wang Fei, Xing Shihe. Progress of the research on crop planting regional planning. Chinese Journal of Agricultural Resources and Regional Planning, 2007, 28(5): 37 40 (in Chinese)

Webster R. Is soil variation random? Geoderma, 2000, 97:149 163

Yao Huarong, Wu Shaohong, Cao Mingming. Optimum allocation of regional land and water resources based on GIS]. Transactions of the CSAE, 2004, 20(2): 31 35.( in Chinese with English abstract)

Yao Rongjiang, Yang Jingsong, Zou Ping. Quantitative Evaluation of the Field Soil Salinity and Its Spatial Distribution Based on Electromagnetic Induction Instruments. Scientia Agricultura Sinica, 2008, 41(2): 460 469 (in Chinese)

Yu Zhengrong, Xin Dehui. Study on method for land use planning and design.Journal of natural resources, 1994, 9(2): 176 184 (in Chinese)

Yuan Xiaoyong, Huang Yuanfang, Gao Rutai, et al. Spatial variability characteristics of farmland soil organic matter in Pinggu District Beijing China. Transactions of the CSAE, 2008, 24(2): 70 76 (in Chinese)

Zhang Shoumei. Advancing agricultural Moderate Mass Production to Change modernization agricultural Development Mode. Chinese agricultural mechanization, 2008, (2):10 13 (in Chinese) 